\section{Síndrome de Goldenhar: Reporte de un Caso y revisión de literatura}

\author{
GoldenharSyndrome: Case Report and literature revision
}

\section{Resumen}

El Síndrome de Goldenhar (SG) es la segunda malformación craneofacial más frecuente; de presentación esporádica o como herencia autosómico-dominante involucra los derivados del primer y segundo arco branquial. Además se ha asociado con la exposición a diferentes fármacos y diabetes materna. Sus características principales son las afecciones oculares, auriculares (oído, pabellón auricular) y vertebrales, de ahí su seudónimo espectro o síndrome óculo-aurículo-vertebral. Presentamos el caso clínico de una niña de 8 años de edad con múltiples anomalías congénitas sugerentes de este síndrome puestos en evidencia mediante un estudio multidisciplinario. Mediante el tratamiento estomatológico integral de los tejidos duros así como la distracción osteogénica de la mandíbula en el Instituto Nacional de Salud del Niño se obtuvieron resultados satisfactorios para la paciente.

Palabras claves: Genética, anomalías congénitas, odontología pediátrica.

\section{Abstract}

Goldenhar syndrome is the second most frequent craniofacial malformation; occur sporadically or as an autosomal-dominant inheritance that involves derivatives of the first and second branchial arch. Furthermore, an association with exposure to different drugs and maternal diabetes has been described. Main features are eye conditions, headphones (ear, pinna) and vertebral, hence its nickname spectrum oculo-auriculo-vertebral. We report the case of a girl of eight years old with multiple congenital anomalies by a multidisciplinary study will highlight the clinical features suggestive of this syndrome. The results were satisfactory for the patients, it was dental treatment and hard tissue distraction osteogenesis of the mandible at the Instituto Nacional de Salud del Niño.

Keywords: Genetics, congenital abnormalities, pediatric dentistry.
Casos Clínicos

\section{Eufemia Isabel Correa-Olaya ${ }^{1}$, José Antonio Rivera-Gavilano', Juan Francisco Oré Acevedo ${ }^{3}$, Vilma Chuquihuaccha Granda ${ }^{1}$}

1 Docente de la Facultad de Odontología UNMSM.

2 Docente de la Facultad de Odontología USMP.

3 Cirujano de Cabeza, Cuello y Maxilofacial del INSN.

Correspondencia:

Mg.Esp Eufemia Isabel Correa-Olaya

Calle Pedro Labarthe 412. Urb. Ingienería, San Martín de Porres

Celular: 996592870

E-mail: femisabel@hotmail.com

Fecha de recepción: 02-09-2013

Fecha de aceptación: 16-09-2013

\section{Introducción}

El Síndrome de Goldenhar fue descrito por primera vez por el médico alemán Carl Ferdinand Von Arlt en 1845; pero Goldenhar, lo definió más claramente en 1952. Siendo Gorlin, genetista orofacial, quien acuñó el término oculoauriculovertebral., ${ }^{1,4}$. El síndrome de Goldenhar conocido como: microsomía hemifacial, espectro óculo-aurículo-vertebral, displasia óculo-aurículovertebral o secuencia facio-aurículo-vertebrales una condición compleja y heterogénea caracterizada por microsomíahemifacial, microtia, apéndices preauriculares, hipoplasia mandibular y anomalías vertebrales como vertebras fusionadas o hemivertebras ${ }^{1}$. (Tabla 1 ).

Presenta una prevalencia estimada con un rango de 1 a 5.600 - 45.000 recién nacidos. Afecta más a hombres que mujeres con una relación 3:2. ${ }^{1-7}$

Puede presentarse de forma leve a severa; los hallazgos faciales son usualmente asimétricos presentándose en forma unilateral en $85 \%{ }^{8}$, y bilateral en $10 \%$ a $33 \%{ }^{6,9},{ }^{10}$ de los casos, ocurriendo principalmente en el lado derecho ${ }^{1,}{ }^{6}$,siendo la mandíbula la más afectada. Existe una clasificación de las deformidades mandibulares en la microsomía hemifacial según Pruzansky ${ }_{11,12}$ (Tabla 2).

Existen varias teorías sobre el origen de este síndrome como es la propuesta por Robinson en donde una disrupción vascular afecta las estructuras del primer y segundo arco branquial alrededor de los días 30 y 45 días de gestación ${ }^{4}$.

Mac-Kenzie habla de la posibilidad de una anormalidad de la arteria estapedial. La arteria estapedial es una vascularización temporal que alimenta el mesodermo del primer y segundo arcos branquiales; aparece como una colateral de la arteria hioides y anastomosa con la arteria faríngea la cual es reemplazada por la carótida externa. La hipótesis formulada por Poswillo habla de una hemorragia intrauterina de la arteria estapedial en el área del primer y se- gundo arco branquial formando un hematoma que posiblemente produciría interacciones epitelio mesinquematosas y se observa necrosis de tejido fino. Se piensa que la hemorragia ocurriría en la sexta semana en que la arteria carótida externa sustituye a la arteria estapedial como surtidor vascular principal de la cabeza y las regiones anteriores del cuello ${ }^{46}$. Este mecanismo explica las anormalidades del oído en este espectro, ya que el primer arco branquial da lugar al primordio del oído anterior y el segundo arco branquial origina el primordio del oído posterior. Además, el conducto auditivo externo deriva de la porción dorsal de la primera hendidura branquial $^{1}$.

Soltan y Holmes en su tiempo comentaron la probabilidad de factores genéticos y vasculares ${ }^{4}$; Fisher y col. demostraron un desbalance en la dosis génica del gen BAPX1 en pacientes afectados ${ }^{13}$. Los genes homeobox MSX juegan un rol crucial en la diferenciación del primer arco branquial y puede explicar la 


\begin{tabular}{|c|c|c|c|}
\hline $\begin{array}{l}\text { Manifestaciones } \\
\text { oculares }\end{array}$ & $\begin{array}{c}\text { Anomalias en } \\
\text { oído }\end{array}$ & $\begin{array}{l}\text { Defectos } \\
\text { vertebrales }\end{array}$ & $\begin{array}{c}\text { Alteraciones } \\
\text { Faciales }\end{array}$ \\
\hline Anoftia & Microtia & Hemivértebras & $\begin{array}{c}1 / 3 \text { superior: } \\
\text { abombamiento frontal }\end{array}$ \\
\hline $\begin{array}{c}\text { Microftalmía } \\
\text { unilateral/bilteral }\end{array}$ & $\begin{array}{l}\text { Apéndices } \\
\text { pre auriculares }\end{array}$ & $\begin{array}{c}\text { Vértebras } \\
\text { super numerarias }\end{array}$ & $\begin{array}{c}\text { 1/3 medio: } \\
\text { hioplasiaesqueletal, } \\
\text { hipoplasia de los } \\
\text { músculos } \\
\text { masticatorios, faciales } \\
\text { y del paladar. } \\
\text { Hipoplasia y mala } \\
\text { posición de los } \\
\text { pabellones auriculares }\end{array}$ \\
\hline Dermoides epibulbares & $\begin{array}{l}\text { Anomalías en el } \\
\text { oído medio }\end{array}$ & Costillas anormales & $\begin{array}{c}\text { 1/3 inferior: } \\
\text { Macrostomía por } \\
\text { extensión del ángulo } \\
\text { bucal del lado } \\
\text { afectado }\end{array}$ \\
\hline $\begin{array}{c}\text { Coloboma de párpado } \\
\text { superior }\end{array}$ & Sordera variable & & \\
\hline $\begin{array}{l}\text { Hipoplasia del nervio } \\
\text { optico }\end{array}$ & $\begin{array}{l}\text { Atresia del } \\
\text { conducto auditivo } \\
\text { externo }\end{array}$ & & \\
\hline \multicolumn{4}{|l|}{$\begin{array}{l}\text { Vasos retinianos } \\
\text { tortuosos }\end{array}$} \\
\hline \multicolumn{4}{|l|}{ Estrabismo } \\
\hline $\begin{array}{l}\text { Agudeza visual } \\
\text { disminuida }\end{array}$ & & & \\
\hline
\end{tabular}

Tabla 2. Clasificación de las de formidades mandibulares en la Microsomía hemifacial según Pruzansky 1969

\begin{tabular}{|c|c|c|}
\hline GRADO I & GRADO II & GRADO III \\
\hline $\begin{array}{l}\text { Presenta una hipoplasia } \\
\text { mínima mandibular, todas } \\
\text { las estructuras se } \\
\text { encuentran presentes }\end{array}$ & $\begin{array}{c}\text { El cóndilo y la rama son más } \\
\text { pequeños, la cabeza del } \\
\text { cóndilo es plana, con } \\
\text { ausencia de cavidad } \\
\text { glenoidea; la apófisis } \\
\text { coronoides puede estar } \\
\text { ausente }\end{array}$ & $\begin{array}{l}\text { La rama mandibular puede } \\
\text { estar reducida a una pequeña } \\
\text { y delgada lámina de hueso o } \\
\text { no existir }\end{array}$ \\
\hline
\end{tabular}

variabilidad y los diferentes grados de severidad en las anomalías del SG; asicomo la teoría de Van Meter y Weaver que sugiere una migración deficiente de las células de la cresta neural ${ }^{1}{ }^{4}$.

Entre las diferentes causas descritas en la literatura están las madres diabéticas que producen elevadas concentraciones de glucosa durante las primeras semanas de gestación originando estrés oxidativo en las células del embrión, se altera la vía del gen Pax3 y ocasiona diversas cromasopatias y malformaciones de las células del tubo neural ${ }^{2}, 369$, Con respecto a las teorías teratogénicas por la ingesta de fármacos durante el embarazo están: el ácido retinoico, la talidomida, la primidona y la cocaína como principales desencadenantes ${ }^{2}, 4,8,9$. Incluso se le relaciona con el uso de vitamina $\mathrm{A}$ en altas concentraciones ${ }^{6}$ y factores ambientales (insecticidas y herbicidas) $^{9}$. En el $10 \%$ de los casos se ha asociado con retraso mental y en el $42 \%$ con síndromes del espectro autista ${ }^{10}$.

El diagnóstico diferencial, se evidencia con los síndromes: Treacher-Collins, Townes-Brocks, Lambert, oculocerebrofacial, branquio- otorenal,cardioesplénico, las disostosisacrofacial de Nager, acrofacialpostaxial, maxilofacial ymandibulofacial. ${ }^{18}$

\section{Reporte de Caso}

Paciente de 8 años 3 meses de edad, producto de la primera gestación (madre de 28 años, ama de casa y padre 30 años, agricultor), sanos y no consanguíneos, no hay antecedente de uso de tóxicos ni patología familiar de importancia. A los 2 meses de gestación le informaron a la madre que tenía amenaza de aborto. No consumió medicamentos solo tomó vitaminas por un mes. Nacida de Parto eutócico, pre término a las 38 semanas. Peso al nacer: 2000 gr y talla: $47 \mathrm{~cm}$. No tuvo lactancia materna, se alimentó con leche de fórmula hasta los 8 meses. A la semana de nacida padeció de bronconeumonía, motivo por el cual estuvo hospitalizada por 7 días en el Hospital María Auxiliadora donde fue diagnosticada con Síndrome de Goldenhar (SG). A los 6 meses de nacida acude al Instituto Nacional de Salud del Niño donde recibe tratamiento multidisciplinario hasta la actualidad.

\section{Diagnóstico}

Presenta Síndrome de Goldenhar, con las siguientes características craneofaciales: microsomia hemifacial izquierda, parálisis facial periférica, desviación de la comisura labial hacia el lado izquierdo y macrostomia (Fig. 1); auditivas: Anotia, ausencia de conducto auditivo externo izquierdo y apéndice pre auricular izquierdo (Fig. 2); oculares: ptosis palpebral izquierda; orales: agenesia de la rama ascendente y cóndilo de la mandíbula izquierda, hipoplasia mandibular, limitación de la apertura bucal. (Fig. 3); anomalías renales: rinón ectópico hipoplásico izquierdo.

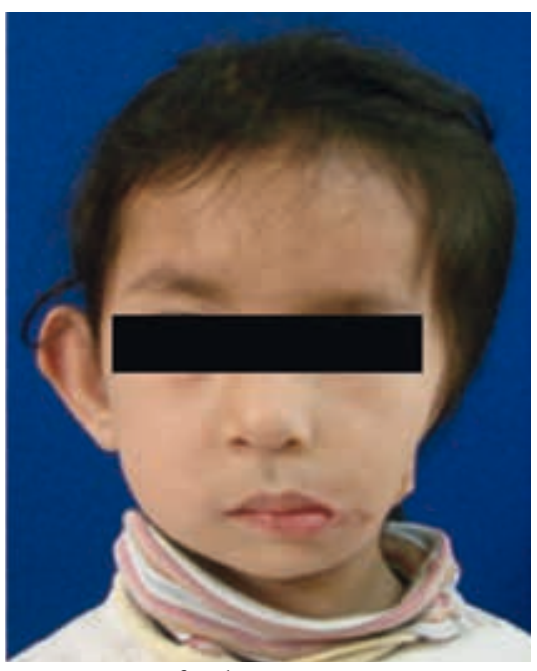

Fig1. Asimetría facial

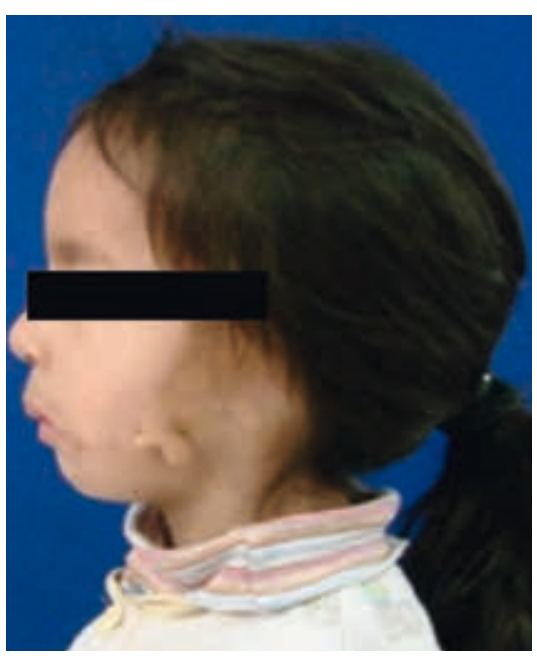

Fig 2. Apéndices preauriculares

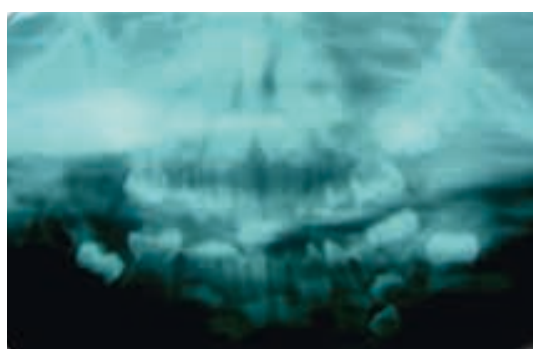

Fig.3. Ortopantomografía: Ausencia del ATM izquierda 
De acuerdo al Estado de Salud Estomatológico:

A nivel de tejidos blandos: anquiloglosia.

A nivel de tejidos duros:

- Caries de esmalte: Piezas 51 (M-D), $52(\mathrm{M}), 55(\mathrm{O}), 61(\mathrm{M}-\mathrm{D}), 62(\mathrm{M})$, $63(\mathrm{~V}), 65(\mathrm{O}), 75(\mathrm{O})$ (Fig. 4 y 5).

- Pulpitis Reversible: Piezas 54, 64, 74 y 84. (Fig. 4 y 5).

- Oclusión: Escalón mesial (derecha) y escalón distal (izquierda). Relación canina Clase III derecha y Clase II izquierda.

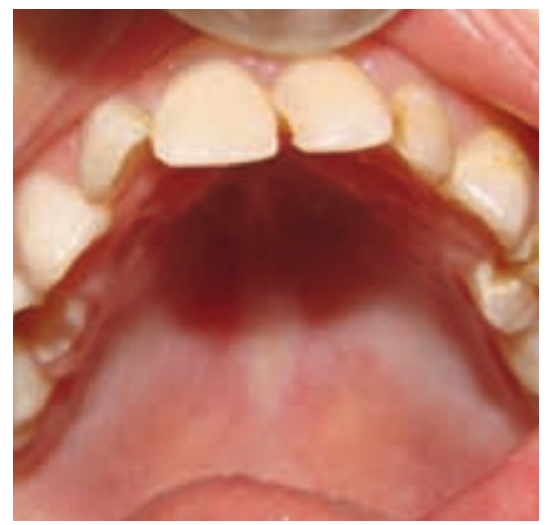

Fig.4. Vista oclusal superior

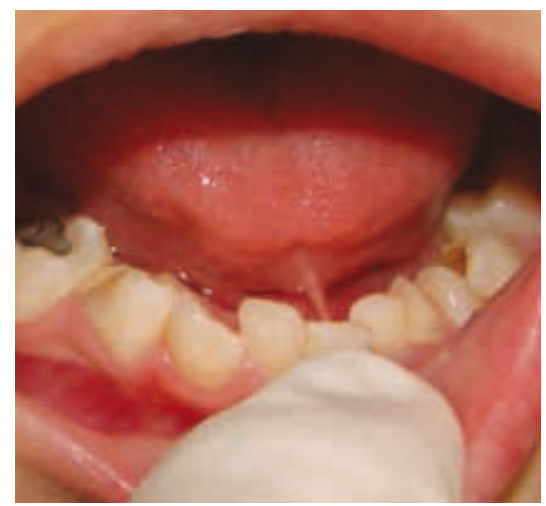

Fig.5. Vista oclusal inferior

\section{Tratamiento}

En el Servicio de Cirugía Plástica se realizó la corrección de macrostomía con Tratamiento Quirúrgico de Queiloplastía Unilateral (abril 2006). El Servicio de Cirugía Buco Maxilofacial realizó Tratamiento Odontológico Integral en Sala de Operaciones. Se realizó procedimientos por cuadrantes: Pulpotomías con Sulfato Férrico al $15,5 \%$ en piezas $54,64,74,84$ y la restauración de las mismas con Ionómero de vidrio (Tipo II Ketac Molar) y resina hibrida (Tetric Ceram bleach LO20). Restauraciones con resina fluida (Tetric flow Bleach) en piezas $51(\mathrm{M}-\mathrm{D}), 52(\mathrm{M}), 55(\mathrm{O}), 61$ (M-D),62 (M), 63(V), 65(O), 75(O) (Fig. 6). (Octubre 2009),

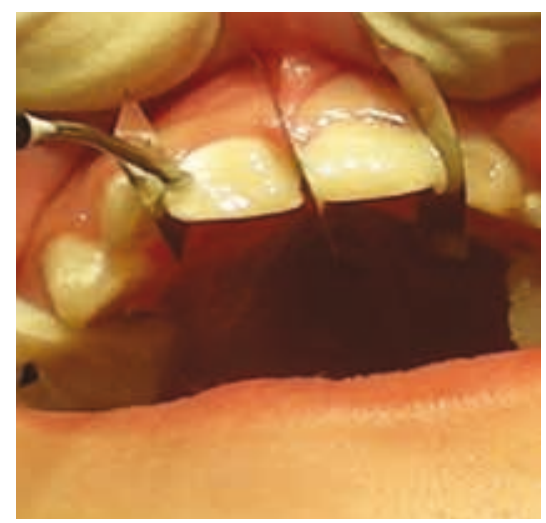

Fig.6. Restauración con Resina fluida en Pzas. 51 y 61

En el Servicio de Cabeza y Cuello debido al diagnóstico de agenesia de la rama mandibular izquierda se realiza la reconstrucción mandibular con colocación de injerto autólogo subcostal de hueso con cartílago de aproximadamente $5 \mathrm{~cm}$ fijado mediante miniplacas, tornillos de $1.3 \mathrm{~cm}$ y alambre (Fig. 7, 8, 9). (Noviembre 2009), se realiza exéresis de apéndice preauricular izquierdo de $2 \times 1 \mathrm{~cm}$ (Incisión Losange). (Enero 2012),

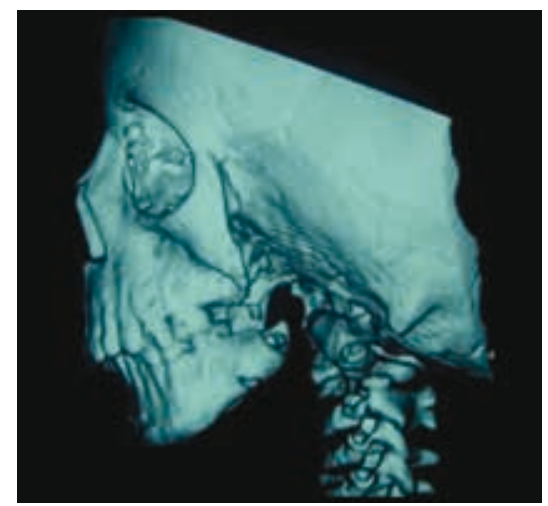

Fig.7. TAC Facial Asimetría izquierda

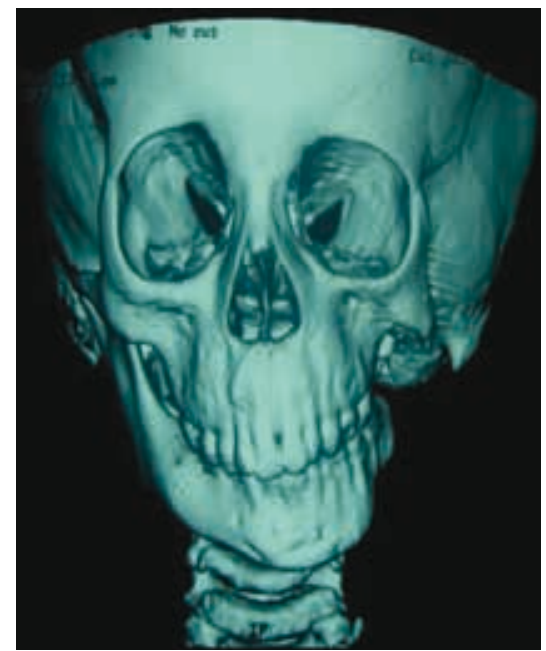

Fig.8. TAC Facial. Ausencia de rama y cóndilo mandibular izquierdo

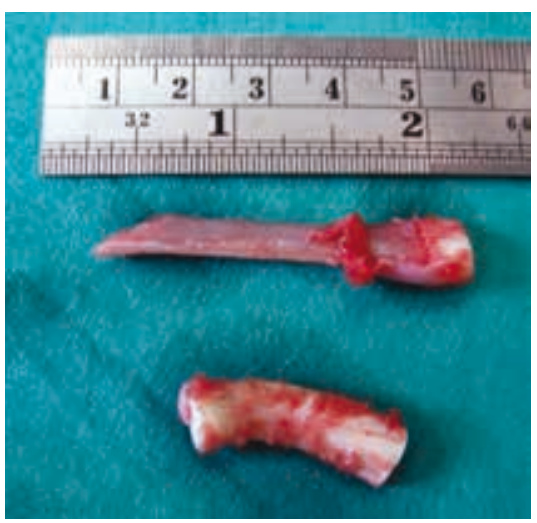

Fig.9. Autoinjerto subcostal

Asimismo, se efectuó una osteomía mandibular con colocación de distractor externo. Incisión a nivel de fondo de surco cuerpo mandibular izquierdo, disección por planos hasta evidenciar mandíbula, incisión lineal de $1 \mathrm{~mm}$ y colocación y fijación de 4 clavos Kischner, osteotomía mandibular, colocación de distractor mandibular izquierdo, sutura por planos (Noviembre 2012). A la semana se efectuó su activación y a los 04 meses se procedió al retiro del distractor (Marzo 2013). (Fig.10, 11).
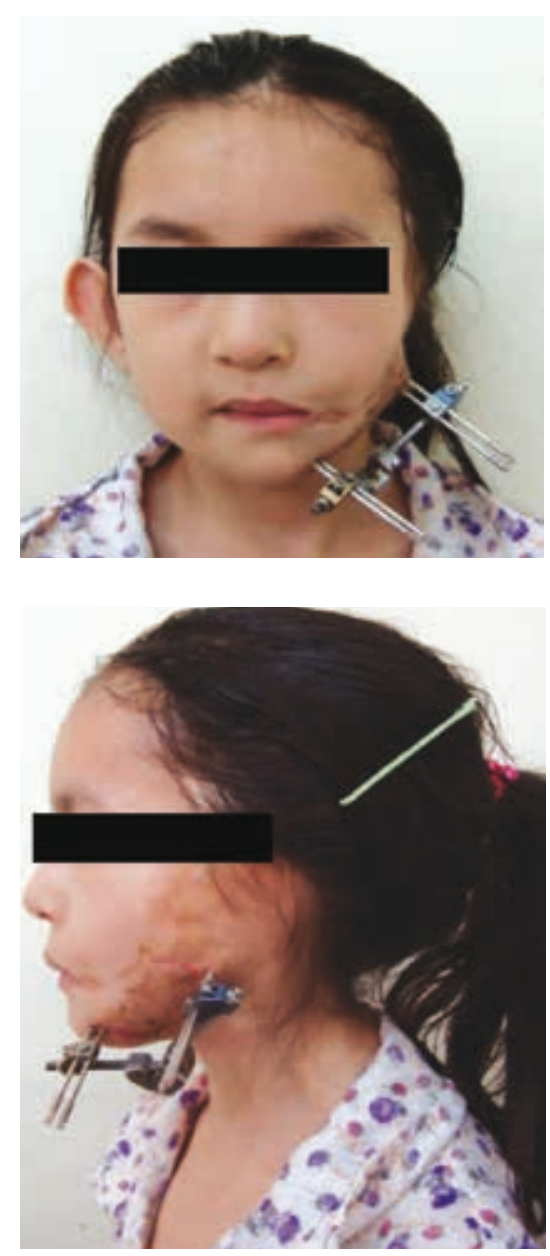

Fig. 10 y 11 . Colocación de Distractor mandibular izquierdo 


\section{Discusión}

El síndrome de Goldenhar (SG) se caracteriza por un espectro de malformaciones faciales, oculares, auriculares con presencia o ausencia de anomalías vertebrales. ${ }^{6}$ Generalmente es unilateral $(85 \%)$ y bilateral $(10-33 \%)^{6},{ }^{10},{ }^{10}$, siendo el lado derecho el más afec$\operatorname{tado}^{16}{ }^{6}$, con una tasa de predilección masculino : femenino de 3:2. En este paciente se presentó en forma unilateral siendo el lado izquierdo el afectado. Resaltando la asimetría facial relacionada con la hipoplasia de tejido blando y óseo. La mandíbula ha sido la más afectada, presentando agenesia de la rama y cóndilo izquierdo, el cuerpo se curva hacia arriba, la barbilla se desvía hacia el lado afectado y el lado opuesto de la mandíbula se observa aplanado ${ }^{11-13}$. La anormalidad en el pabellón auricular izquierdo tipo microtia sin presencia de conducto auditivo externo resulta ser un defecto relevante puesto que este es un signo que se presenta comúnmente en este síndrome ${ }^{10}$.

Este síndrome es el segundo tipo de malformación craneofacial más frecuente, después de la fisura y labio hendido siendo su etiología desconocida ${ }^{4}$, pero se ha relacionado con factores ambientales (insecticidas y herbicidas) lo cual podría tener relación con el caso presentado, ya que el padre de la paciente se dedica a la agricultura. Dentro de las características clínicas asociadas a este síndrome destacan las que afectan el sistema nervioso central, sistema cardiaco, aparato respiratorio, tracto gastrointestinal y sistema renal. ${ }^{4}{ }^{10}$ Resaltando en este caso clínico alteraciones renales con la presencia de riñón ectópico hipoplásico izquierdo presentándose en menos del $10 \%$ de casos reportados.

El tratamiento del SG es muy complejo, requiere de la participación de un equipo multidisciplinario, incluye al pediatra, genetista, cirujano plástico, cirujano de cabeza y cuello, oftalmólogo, odontopediatra, ortodoncista, logopedas ${ }^{11},{ }^{12},{ }^{15}$.

La limitación en la apertura bucal y en el desarrollo mandibular; provocaron que la intubación sea muy difícil para el tratamiento odontológico integral en sala de operaciones realizando dicho tratamiento a través de la técnica anestésica para intubación con Fibrobron$\operatorname{coscopia}^{16}$.

Para el tratamiento de pulpotomías, se utilizó el sulfato férrico porque reduce el tiempo de exposición (15 s a 1 minuto), además de tener acción he- mostática al entrar en contacto con la sangre forma un complejo proteínico y la membrana de este complejo sella los vasos con ello minimiza las posibilidades de inflamación y resorción interna además tiene características bactericidas permiten una cavidad limpia y estéril, que nos permite tener una pulpa radicular remanente completamente intacta y permitiendo que la pulpa hagas sus funciones de defensa y formación ${ }^{16,17}$.

Las técnicas recomendadas para el tratamiento de la agenesia de la rama de la mandíbula giran en su mayoría alrededor de las alternativas quirúrgicas, la mayoría de los autores recomiendan la cirugía temprana a partir de los 3 años de edad, como se ha realizado en este caso reportado usando tejido autólogo subcostal de hueso y cartílago fijado mediante miniplacas y tornillos de titanio a la mandíbula, con el objetivo de establecer un centro de crecimiento que facilite el normal desarrollo óseo facial, restablecer la simetría facial, y reparar las deformidades faciales. Sin embargo, las tendencias más recientes describen técnicas quirúrgicas orientadas al tratamiento mediante la distracción osteogénica con aditamentos desarrollados específicamente para evitar la necesidad de reintervención para remover los tornillos el cual se ha realizado exitosamente en nuestra paciente ${ }^{11},{ }^{12}$.

Se puede decir que a pesar de la complejidad estética y funcional y de las otras alteraciones, la paciente se conduce con aceptable comunicación y adecuado desenvolvimiento social.

\section{Conclusiones}

El diagnóstico temprano es de vital importancia para poder establecer un protocolo de tratamiento adecuado, mediante la exploración ultrasonográfica, permite detectar alteraciones morfológicas de su desarrollo y planificar la futura atención del recién nacido afectado.

El manejo de un equipo médico multidisciplinario para la corrección de las diferentes malformaciones, es importante para obtener un esultado funcional y estético satisfactorio, siempre con apoyo psicológico para el manejo de posibles secuelas.

El pronóstico de pacientes con esta enfermedad depende del tipo de malformaciones con las que se relaciona, las malformaciones cardiacas y del sistema nervioso central representan las de mayor mortalidad, la mayoría de los niños presentan un desarrollo normal.

\section{Referencias Bibliográficas}

1. Cammarata-Scalisi F, Zerpa R, Stock F, Cammarata-Scalisi ME, Cammarata-Scalisi G, Machado J, Guerrero Y.Diagnóstico oportuno del espectro oculo-auriculo-vertebral (Síndrome de Goldenhar). Can Pediatr 2012;36(1):25-9.

2. Shawky R, Zahra S. Goldenhar syndrome with skin tags on the chest wall. The Egyptian Journal of Medical Human Genetics 2011;12:217-20.

3. Kerckoff H, Retamoza B, Bautista A. Espectro oculoauriculovertebral y malformaciones cerebrales en un neonato de madre diabética. GinecolObstet 2008; 76(11):691-4.

4. Kershenovich R, Garrido LM, Burak A. Síndrome de Goldenhar: Reporte de un caso.Mediographic Artemisa. Acta médica Grupo Angeles. 2007; 5(4):214-20.

5. Mahore A, Dange N, Nama S, Goel A. Facio-auriculo-vertebrocephalic spectrum of Goldenhar syndrome. Neurology India. 2010; 58(1):141-4.

6. Reyes-Velásquez JO, Barrera-Vera H. Sindrome de Goldenhar. Med Oral 2010; 12(3):113-7.

7. Tuna E, Orino D, Ogawa K, Yildirim, Seymen F, et al. Craniofacial and dental characteristics of Goldenhar syndrome: a report of two cases. Journal of oral Science 2011;53(1):121-124.

8. Mehta B, Nayak Ch, Savant S, Amlandi S. Goldenhar syndrome with unusual features. Indian J Dermatol Venereo Leprol 2008;74(3):254-256.

9. Siddique M, Hossain J, Abedin MJ, Parvez M. Goldenhar Syndrome- A Case Report. Journal of Bangladesh College of Physicians and surgeons 2010;28(3):193-5.

10. Panchajoa HM, Saldarriaga W, Isaza C. Un caso de espectro oculoauriculovertebral con meningocele occipital. Med UNAB 2006; 9(2):164-167.

11. Quirós O, D’ Escriban de Saturno L. Agenesia del cóndilo, crecimiento de cóndilo suplementario en paciente tratado con ortopedia funcional de los maxilares, sin cirugía. Rev lationamericana de Ortodoncia y Ortopedia 2003:1-8 
12. Leiva N, Castellón L, Agurto P, Morovic C, Calvo L. MicrosomíaHemifacial. Tratamiento de un Paciente en Crecimiento.Rev Dental de Chile 2010;101(3):31-7.

13. Fischer S, Lüdecke HJ, Wieczorek D, BöhringerS, Horsthemke B. Histone acetylation dependent alle-lic expression imbalance of BAPX1 in patients with the oculoauriculo-vertebral spectrum. Hum Mol Genet 2006;15(4):581-7.
14. Rosa RF, Da Silva AP, Goetze TB, Bier A, De Almeida ST, Paskulin GA, et al. Ear abnormalities in patients with oculo-auriculo-vertebral spectrum (Goldenhar syndrome).Braz J Otorhinolaryngol. 2011;77(4):455-60.

15. Moreno A, et al. Evaluación preoperatoria del síndrome de Goldenhar para rehabilitación bucal bajo anestesia general. Reporte de un caso. Arch Inv Mat Inf 2011;3(2):81-87.
16. Orellana JE, Gonzales JS, Nava JF, Ponce M. Comparación de la efectividad del Sulfato Férrico como método alternativo en Pulpotomías infantiles in vivo. Revista Latinoamericana de Ortodoncia y Odontopediatría 2011:1-8

17. Zaror C, Vergara C, Diaz J, Aracena D. Pulpotomías con sulfato férrico y MTA en dientes primarios: Serie de casos. Int. J. Odontostomat 2011;5(1):77-82. 